\title{
Melatonin Relations With Respiratory Quotient Weaken on Acute Exposure to High Altitude
}

\begin{abstract}
Marcelo Tapia', Cristian Wulff-Zottele ${ }^{2}$, Nicole De Gregorio ${ }^{3}$, Morin Lang', Héctor Varela ${ }^{4}$, María Josefa Serón-Ferré3 ${ }^{3}$ Ennio A. Vivaldi ${ }^{3}$, Oscar F. Araneda ${ }^{5}$, Juan Silva-Urra ${ }^{2}$, Hanns-Christian Gunga ${ }^{6}$ and Claus Behn ${ }^{3,7 *}$

${ }^{1}$ OwI Capacitaciones y Asesorías SpA, Antofagasta, Chile, ${ }^{2}$ Facultad de Ciencias de la Salud, Universidad de Antofagasta, Antofagasta, Chile, ${ }^{3}$ Facultad de Medicina, Instituto de Ciencias Biomédicas, Universidad de Chile, Santiago, Chile, ${ }^{4}$ Facultad de Ciencias Básicas, Universidad de Antofagasta, Antofagasta, Chile, ${ }^{5}$ Facultad de Medicina, Universidad de los Andes, Santiago, Chile, ${ }^{6}$ Center for Space Medicine and Extreme Environments, Institute of Physiology, Charité Universitätsmedizin Berlin, Berlin, Germany, ${ }^{7}$ Facultad de Medicina, Universidad San Sebastián, Santiago, Chile
\end{abstract}

\section{OPEN ACCESS}

Edited by:

Jean-Paul R. Richalet, Université Paris 13, France

Reviewed by:

Paul Kenneth Witting,

University of Sydney, Australia Andrew T. Lovering University of Oregon, United States

${ }^{*}$ Correspondence: Claus Behn clausbehnthiele@gmail.com

Specialty section:

This article was submitted to Integrative Physiology, a section of the journal Frontiers in Physiology

Received: 28 December 2017 Accepted: 07 June 2018

Published: 29 June 2018

Citation:

Tapia M, Wulff-Zottele C De Gregorio N, Lang M, Varela $H$, Serón-Ferré MJ, Vivaldi EA Araneda OF, Silva-Urra J, Gunga $\mathrm{H}-\mathrm{C}$ and Behn C (2018) Melatonin Relations With Respiratory Quotient Weaken on Acute Exposure to High Altitude. Front. Physiol. 9:798. doi: 10.3389/fphys.2018.00798
High altitude $(\mathrm{HA})$ exposure may affect human health and performance by involving the body timing system. Daily variations of melatonin may disrupt by HA exposure, thereby possibly affecting its relations with a metabolic parameter like the respiratory quotient $(R Q)$. Sea level $(S L)$ volunteers ( 7 women and 7 men, $21.0 \pm 2.04$ y) were examined for daily changes in salivary melatonin concentration (SMC). Sampling was successively done at SL (Antofagasta, Chile) and, on acute HA exposure, at nearby Caspana (3,270 $\mathrm{m}$ asl). Saliva was collected in special vials (Salimetrics Oral Swab, United Kingdom) at sunny noon $\left(\mathrm{SMC}_{\mathrm{D}}\right)$ and in the absence of blue light at midnight $\left(\mathrm{SMC}_{\mathrm{N}}\right)$. The samples were obtained after rinsing the mouth with tap water and were analyzed for SMC by immunoassay (ELISA kit; IBL International, Germany). RQ measurements $(n=12)$ were realized with a portable breath to breath metabolic system (Oxicon ${ }^{\mathrm{TM}}$ Mobile, Germany), between 8:00 PM and 10:00 PM, once at either location. At SL, $\mathrm{SMC}_{\mathrm{D}}$, and $\mathrm{SMC}_{\mathrm{N}}$ values (mean $\pm \mathrm{SD}$ ) were, respectively, $2.14 \pm 1.30$ and $11.6 \pm 13.9 \mathrm{pg} / \mathrm{ml}(p<0.05)$. Corresponding values at $\mathrm{HA}$ were $8.83 \pm 12.6$ and $13.7 \pm 16.7 \mathrm{pg} / \mathrm{ml}$ (n.s.). RQ was $0.78 \pm 0.07$ and $0.89 \pm 0.08$, respectively, at $\mathrm{SL}$ and HA $(p<0.05)$. Differences between $\mathrm{SMC}_{N}$ and $\mathrm{SMC}_{\mathrm{D}}\left(\mathrm{SMC}_{\mathrm{N}}-\mathrm{SMC}_{\mathrm{D}}\right)$ strongly correlate with the corresponding $R Q$ values at $S L(r=-0.74)$ and less tight at $H A(r=-0.37)$. Similarly, mean daily SMC values $\left(\mathrm{SMC}_{\overline{\mathrm{x}}}\right)$ tightly correlate with $\mathrm{RQ}$ at $\mathrm{SL}(r=-0.79)$ and weaker at $\mathrm{HA}(r=-0.31)$. $\mathrm{SMC}_{\mathrm{N}}-\mathrm{SMC}_{\mathrm{D}}$, as well as, $\mathrm{SMC}_{\overline{\mathrm{x}}}$ values at $\mathrm{SL}$, on the other hand, respectively, correlate with the corresponding values at $\mathrm{HA}(r=0.71$ and $r=0.85)$. Acute exposure to HA appears to loosen relations of SMC with $R Q$. A personal profile in daily SMC variation, on the other hand, tends to be conserved at HA.

Keywords: melatonin, circadian rhythm, high altitude, respiratory quotient, body timekeeping

\section{INTRODUCTION}

Contemporary working conditions, tend to challenge the human body internal timing system. Jet-lag (Coste et al., 2004), and extreme environments (Arendt, 2012; Najjar et al., 2014), affect circadian rhythms. Circadian misalignment sets the basis for metabolic disorders and cell cycle alterations that ultimately implicate risks at work and disease (Archer et al., 2014; 
Smolensky et al., 2016; Swanson et al., 2016). Circadian deregulation on high altitude (HA) exposure (Mortola, 2007, 2017) added to desynchronization by shift-work (Andlauer et al., 1979; Reinberg and Ashkenazi, 2008; Mirick et al., 2013) may well represent a factor involved in the lethal outcome of remote HA mining (Zaldívar Larraín, 2013).

Living beings synchronize with periodic environmental challenges. Various Zeitgebers, among them the daily light/dark cycle synchronize endogenous time keepers, the biological clocks (Reddy and O’Neill, 2010; Thut et al., 2012; Tsang et al., 2013). Rhythms result from a changing balance between activators and repressors in a negative feedback loop or between synthesis and degradation rates of oscillator components (Pulivarthy et al., 2007; see also Li et al., 2017). Intersecting with cellular biochemistry, multiple oscillators finally yield physiological, and behavioral rhythms (Top and Young, 2017). Countless oscillators, with widely differing oscillation periods, constitute the body timing system (Beale et al., 2016; Tran et al., 2016). Interacting among themselves (Schroeder and Lakatos, 2009; Zelano et al., 2016), the oscillators represent temporal reference frames for each other (Thut et al., 2012; Thurley et al., 2017). A complex information handling framework thus results (Rapp, 1987; Lloyd and Rossi, 1993).

Melatonin synchronizes cellular clocks with its own epiphyseal secretion, the latter being driven, via suprachiasmatic nuclei (Coomans et al., 2013), by the daily light/dark cycle determined by Earth rotation (Arendt, 1996; Chakir et al., 2015; Hardeland, 2015). Rhythm synchronization integrates body functions, both by local (Lin et al., 2017), as well as, by systemic means (Pfeffer et al., 2017). Melatonin ( $N$-acetyl-5-methoxytryptamine), an ubiquitous, pleiotropic, and multitasking indoleamine (for recent reviews see Luchetti et al., 2010; Reiter et al., 2010; Hardeland et al., 2012) derives from tryptophan successively being transformed into serotonin and $N$-acetylserotonin. An $\mathrm{N}$-acetyltransferase, involved in melatonin synthesis, is inhibited by light. Melatonin, thus, acts as a chemical transmitter of darkness (Tan et al., 2010; Hardeland et al., 2011). The non-image-forming vision system entraining body function rhythmicity via melatonin also implicates a subpopulation of retinal ganglion cells (ipRGCs $\approx 1 \%$ of the retinal ganglion cell population; Panda et al., 2003). The ipRGCs depolarize in response to photostimulation (Berson et al., 2002). Melanopsin, the photopigment of ipRGCs, absorbs light at aprox. $480 \mathrm{~nm}$, the wavelength most effective in suppressing melatonin secretion (for a recent review see Lucas et al., 2014). Notably, melanopsin is also present in epithelial cells of the lens (Alkozi et al., 2017).

Melatonin involvement in overall circadian regulation relates to energy metabolism (Peschke et al., 2013; Cipolla-Neto et al., 2014) including termoregulation (Gubin et al., 2006; Kräuchi et al., 2006) and redox status (Maciel et al., 2010; JiménezOrtega et al., 2012; Tan et al., 2013; Cudney et al., 2014) acting, among others, as a natural antioxidant (Nehela and Killiny, 2018). Melatonin targets genes (Unfried et al., 2010; Hardeland et al., 2011; Torres-Farfán et al., 2011), the epigenome (Korkmaz et al., 2012; Haim and Zubidat, 2015), as well as, mitochondria (Acuña-Castroviejo et al., 2003; Maciel et al., 2010).
High altitude exposure may affect melatonin rhythm by lack of oxygen. Hypoxia, the lack of oxygen as related to aerobic energy requirements (Connett et al., 1990), delays the phase of melatonin rhythm (Coste et al., 2009). Untreated obstructive sleep apnoea syndrome, a clinical condition implicating intermittent hypoxia, leads to an early morning plateau of plasma melatonin concentration. This morning plateau of melatonin is reversed into a night time peak by increasing oxygen supply via CPAP device application in treated obstructive sleep apnoea patiernts (Hernández et al., 2007). Hypoxia applied for two hours in a hypobaric chamber (simulating $8,000 \mathrm{~m}$ a.s.l.) increases plasma melatonin concentration in rats (Kaur et al., 2002). This body timing system, thus, may be alterated by an environmental challenge such as a rapid ascent from sea level (SL) up to 3,000 m a.s.l., as usual in Chilean Andes. Respiratory quotient (RQ) elevation on HA exposure indicates an increase of glucose utilization under that condition. Insulin-regulated pathways depend on integrity of biological clocks (McGinnis et al., 2017). We, thus, examined effects of acute exposure at HA on the circadian rhythm of the chronotropic neurohormone melatonin and its relation with a metabolic parameter like $R Q$, the latter representing, a point of reference for energy metabolism at HA.

\section{MATERIALS AND METHODS}

\section{Subjects}

Fourteen healthy volunteers (Table 1), all of them students enrolled in Physical Education Pedagogy at University of Antofagasta, volunteered for the present study in the context of a wider HA research project (FONDECYT 1100161). Having previously been approved by the Ethics Committee of the Faculty of Medicine, University of Chile, the latter project was also endorsed by Bioethical Committee of Faculty of Health Sciences, University of Antofagasta, considering the principles and practices stated in the Declaration of Helsinki for studies of human beings. A written informed consent was obtained from each subject finally participating in the study.

\section{Study Design}

The volunteers were examined for salivary melatonin concentration (SMC) at SL, the site of their usual residence. Cardio-respiratory parameters could be obtained in only 12 of them (Table 2). Corresponding measurements at HA were done

TABLE 1 | Body dimensions of the volunteers.

\begin{tabular}{lcccc}
\hline \multicolumn{5}{c}{ Physical parameters of the volunteers (mean \pm SD) } \\
\hline & Age (years) & Weight (kg) & Height (cm) & $\begin{array}{c}\text { Body mass } \\
\text { index (kg/m } \mathbf{2})\end{array}$ \\
\hline Women $(n=7)$ & $21.7 \pm 2.63$ & $64.7 \pm 12.8$ & $163 \pm 3.40$ & $24.2 \pm 4.48$ \\
Men $(n=7)$ & $20.3 \pm 0.95$ & $71.6 \pm 5.77$ & $174 \pm 6.07$ & $23.8 \pm 3.02$ \\
Total $(n=14)$ & $21.0 \pm 2.04$ & $68.1 \pm 10.2$ & $169 \pm 7.19$ & $24.0 \pm 3.68$ \\
\hline
\end{tabular}

Parameters measured at SL. 
TABLE 2 | Cardio-respiratory parameters at SL (Antofagasta) and HA (Caspana, $3,270 \mathrm{~m}$ a.s.l.).

\begin{tabular}{lrr}
\hline \multicolumn{3}{c}{ Cardio-respiratory parameters of the volunteers $(\boldsymbol{n}=\mathbf{1 2})$} \\
\hline & \multicolumn{1}{c}{ SL } & HA \\
\hline $\mathrm{HR}($ beats $/ \mathrm{min})$ & $67.1 \pm 9.55$ & $90.3 \pm 12.1^{*}$ \\
$\mathrm{VE}(\mathrm{l} / \mathrm{min})$ & $9.54 \pm 1.19$ & $15.4 \pm 4.56^{*}$ \\
$\mathrm{BR}($ breaths/min) & $15.3 \pm 4.27$ & $25.9 \pm 5.56^{*}$ \\
$\mathrm{VO}_{2}(\mathrm{ml} / \mathrm{min})$ & $300.3 \pm 42.6$ & $376.2 \pm 86.7^{*}$ \\
$\mathrm{VCO}_{2}(\mathrm{ml} / \mathrm{min})$ & $233.8 \pm 39.9$ & $336.2 \pm 96.0^{*}$ \\
$\mathrm{HbO}_{2} \mathrm{sat}(\%)$ & $99.7 \pm 0.47$ & $95.8 \pm 1.07^{*}$ \\
$\mathrm{RQ}$ & $0.78 \pm 0.07$ & $0.89 \pm 0.08^{*}$
\end{tabular}

The asterisk denotes the difference between SL and HA values being significant $(p<0.05)$. HR, heart rate; VE, pulmonary ventilation; $B R$, breathing rate; $\mathrm{VO}_{2}$, oxygen flux; $\mathrm{VCO}_{2}$, carbon dioxide flux; $\mathrm{HbO}_{2}$ sat, hemoglobin oxygen saturation; $R Q$, respiratory quotient.

in the context of a pedagogic field trip, on the day after arriving by bus, at Caspana (3,270 $\mathrm{m}$ a.s.l.), a small village located in the Andes, $300 \mathrm{~km}$ east from Antofagasta.

\section{Measurements}

\section{Salivary Melatonin Concentration}

At SL, as well as, at the HA site, the subjects were required to provide saliva samples for SMC determination, with sun light at midday $\left(\mathrm{SMC}_{\mathrm{D}}\right)$ and dim, ordinary bulb light, at midnight $\left(\mathrm{SMC}_{\mathrm{N}}\right)$. After rinsing the mouth with tap water, samples of saliva ( $1.5 \mathrm{ml}$ aprox.) were collected into special vials (Salimetrics Oral Swab, United Kingdom), The saliva samples were handled using gloves, coded and stored in liquid nitrogen, to be later on analyzed for SMC with an ELISA kit (IBL International, Germany) in an independent commercial laboratory (Red Lab S.A., Santiago, Chile). $\mathrm{SMC}_{\mathrm{N}}-\mathrm{SMC}_{\mathrm{D}}$ and $\mathrm{SMC}_{\overline{\mathrm{x}}}$ are, respectively, assumed to represent the amplitude of daily SMC change and the average of both day and night SMC value per subject.

\section{Respiratory Quotient}

Cardio-respiratory parameters were determined under resting conditions, after sitting for $5 \mathrm{~min}$. The measurements were done between 8:00 and 10:00 PM, both at SL and HA, once at either location. Evening meals consisted of bread and cheese at SL, as well as at $\mathrm{HA}$. Along a $3 \mathrm{~min}$ equilibration period, respiratory $\mathrm{CO}_{2}$ and $\mathrm{O}_{2}$ fluxes could be measured in 12 of the 14 subjects with a portable metabolic system, including a breath-to-breath spirometer (Oxicon ${ }^{\mathrm{TM}}$ Mobile, Germany). RQ was calculated as the ratio between mean $\mathrm{CO}_{2}$ flux and mean $\mathrm{O}_{2}$ flux.

\section{Statistics}

Mean values are expressed \pm SD. ANOVA for repeated measurements was applied for comparisons between $\mathrm{SMC}_{\mathrm{D}}$ and $\mathrm{SMC}_{\mathrm{N}}$ at SL and HA. Pearson's correlation coefficient and Student's $t$-test were, respectively, applied for analysis of correlations and for comparison between SL and HA. Calculations were done with the aid of SPSS 22 IBM software package. Statistic significance was established at the $p<0.05$ level.

\section{RESULTS}

Age and body mass index were rather similar in women and men volunteering in the present study (Table 1). Cardiorespiratory parameters of the volunteers significantly changed on HA exposure as compared to SL (Table 2). Figure 1 shows mean values of SMC at day and night, both at $\mathrm{SL}\left(\mathrm{SL}_{\mathrm{D}}, \mathrm{SL}_{\mathrm{N}}\right)$ and $\mathrm{HA}$ $\left(H A_{D}, H A_{N}\right)$. Mean SMC values in either those conditions were similar in women and men (data not shown). Daily variations of SMC observed at SL vanish at $\mathrm{HA}$. $\mathrm{SMC}_{\mathrm{N}}-\mathrm{SMC}_{\mathrm{D}}$ and $\mathrm{SMC}_{\overline{\mathrm{x}}}$, respectively, depict, for the present work, the amplitude of circadian melatonin rhythm and the average value around which the oscillation occurs. These parameters strongly correlate one with the other at SL. At HA, on the contrary, this correlation weakens (Figure 2). RQ-SMC $C_{D}$ relation appears to be strong at SL and weak at HA (Figure 3A). Similarly, the RQ-SMC relation appears to be tighter at SL than at HA (Figure 3B). Both, $\mathrm{SMC}_{\mathrm{N}}-\mathrm{SMC}_{\mathrm{D}}$ (Figure 3C), as well as, $\mathrm{SMC}_{\overline{\mathrm{x}}}$ (Figure 3D), also correlate with RQ more strongly at SL than at HA

$S M C_{\overline{\mathrm{x}}}$ values at SL strongly correlate with those at HA (black circles, Figure 4). Similarly, $\mathrm{SMC}_{\mathrm{N}}-\mathrm{SMC}_{\mathrm{D}}$ at $\mathrm{SL}$ also tightly correlate with the corresponding values at HA (white circles, Figure 4). As also shown in Figure 4, the former and the latter relation, respectively, locate mainly above and below the middle line $(y=x)$.

\section{DISCUSSION}

Mean $\mathrm{SMC}_{\mathrm{N}}$ and $\mathrm{SMC}_{\mathrm{D}}$ values differ at SL but not at $\mathrm{HA}$ (Figure 1). $\mathrm{SMC}_{\mathrm{N}}$ and $\mathrm{SMC}_{\mathrm{D}}$, as well as, $\mathrm{SMC}_{\mathrm{N}}-\mathrm{SMC}_{\mathrm{D}}$ and $\mathrm{SMC}_{\overline{\mathrm{x}}}$, correlate with RQ strongly at SL and much less so at HA (Figure 3). Melatonin circadian rhythm, thus, may lose at HA its synchronizing grip on aspects related with energy metabolism. Individual $\mathrm{SMC}_{\overline{\mathrm{x}}}$ and $\mathrm{SMC}_{\mathrm{N}}-\mathrm{SMC}_{\mathrm{D}}$ values at $\mathrm{SL}$, on the other hand, strongly correlate with the corresponding ones at

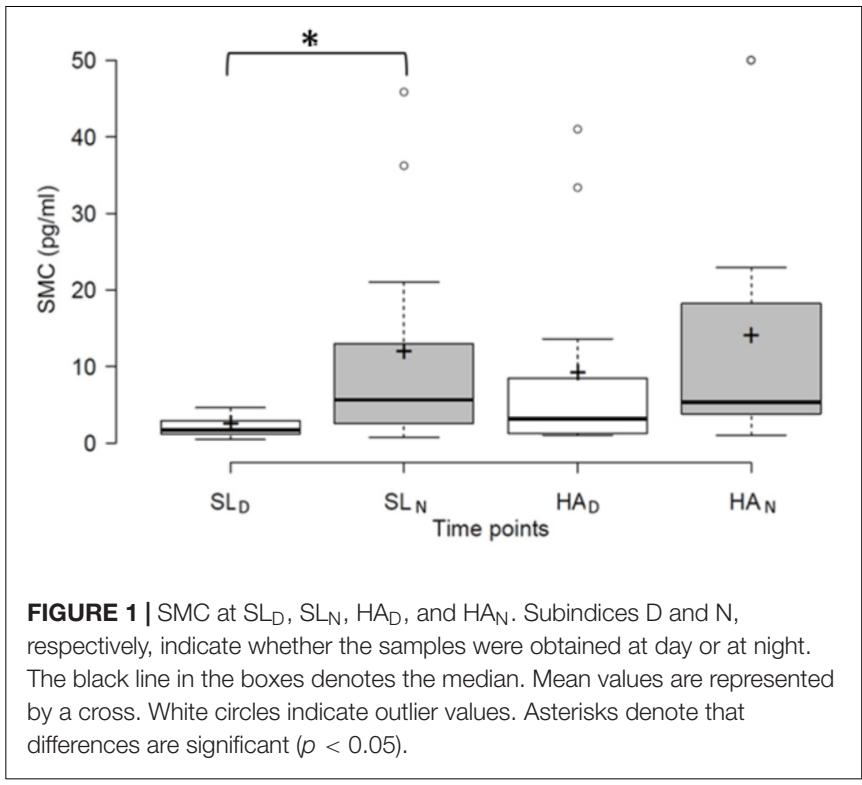




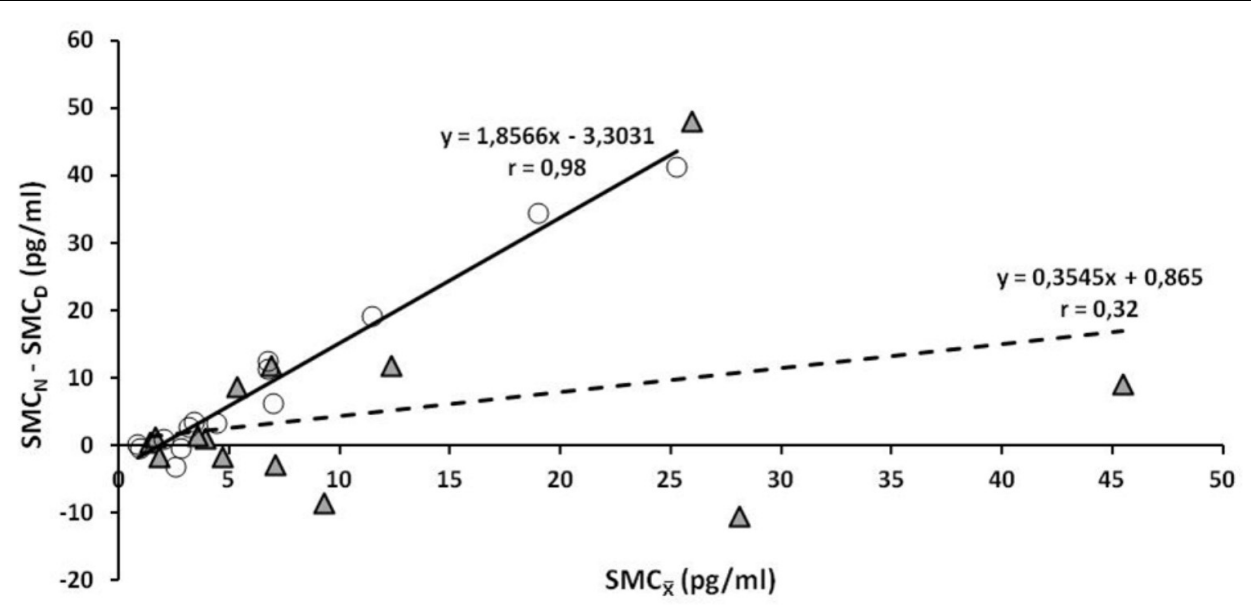

FIGURE $2 \mid S M C_{N}-S M C_{D}$ vs. $S M C_{\bar{x}}$ values at $S L$ and $H A$. Simple linear regression of the relation between $S M C_{N}-S M C_{D}$ and $S M C_{\bar{x}}$ at $S L$ (white circles) and $H A$ (gray triangles), are depicted with continuous and dashed line, respectively.
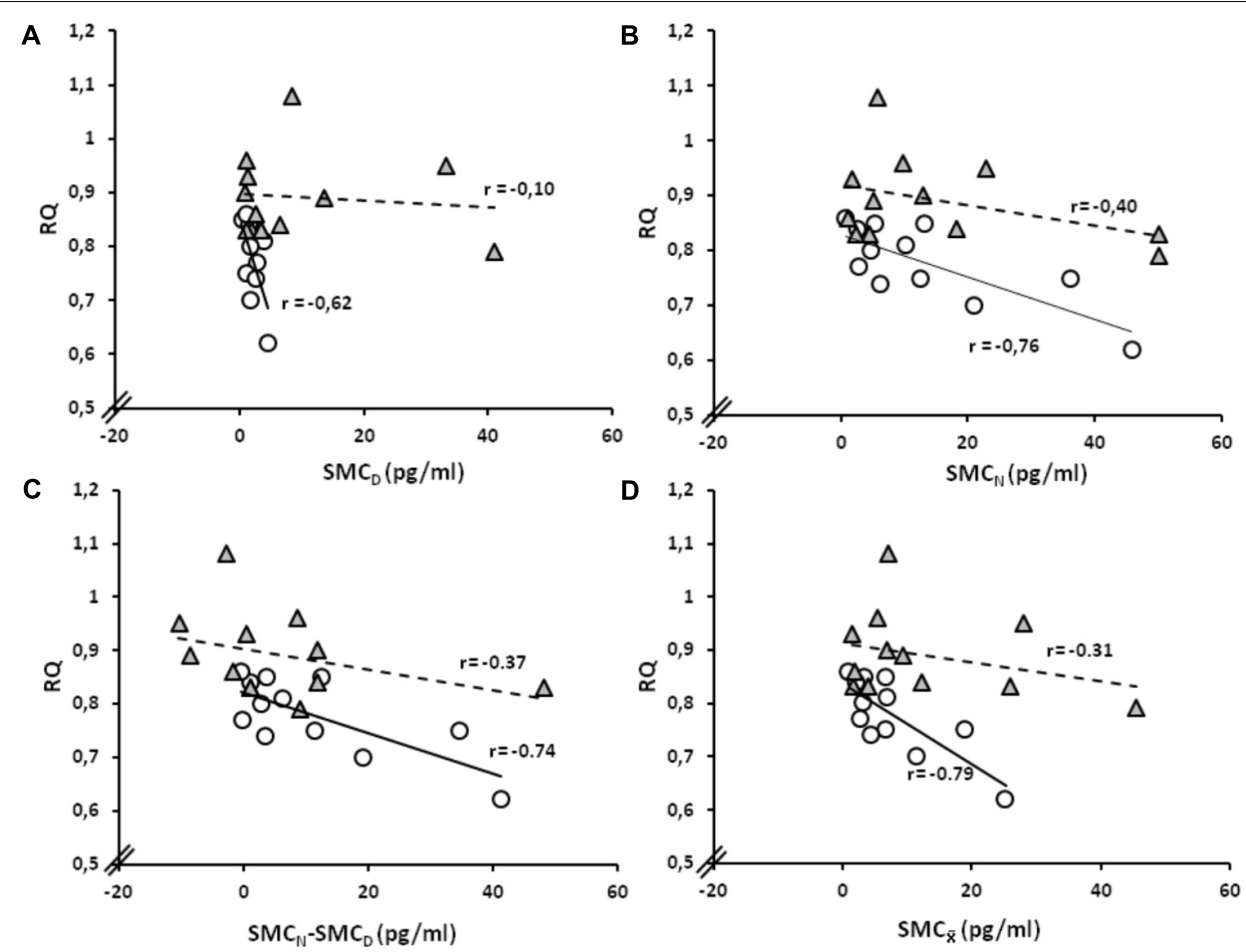

FIGURE 3 I SMC values as related to RQ. (A) Simple linear regression of the relation between $R Q$ and $S M C_{D}$ at $S L$ and $H A$. (B) Simple linear regression of the relation between $R Q$ and $S M C_{N}$ at $S L$ and $H A$. (C) Simple linear regression of the relation between $R Q$ and $S M C_{N}-S M C_{D}$ at $S L$ and at $H A$. (D) Simple linear regression between $\mathrm{RQ}$ and $S M C_{\bar{x}}$ at $S L$ and $H A$. White circles and gray triangles, respectively, represent $S L$ and $H A$ values $(n=12)$.

HA (Figure 4). Although being distorted at HA (Figures 1-3), an individual profile of circadian melatonin rhythmicity, thus, seems to persist under the latter condition (Figure 4). Such an individual profile of circadian melatonin rhythmicity may in the future be explored for its potential to predict the capacity for adequately dealing with challenges of the body timing system.

Salivary melatonin has been validated as an adequate marker for phase typing of circadian regulation (Voultsios et al., 1997).
Although representing only one third of plasma melatonin concentration (Benloucif et al., 2008), SMC adequately relates to the latter (Voultsios et al., 1997). Hyposalivation and low melatonin levels may limit the reliability of SMC, as measured by radioimmunoassay in the elderly (Gooneratne et al., 2003). Liquid chromatography combined with mass spectrometry, on the other hand, revealed SMC values to exceed free plasma melatonin concentration on average by $36 \%$ 


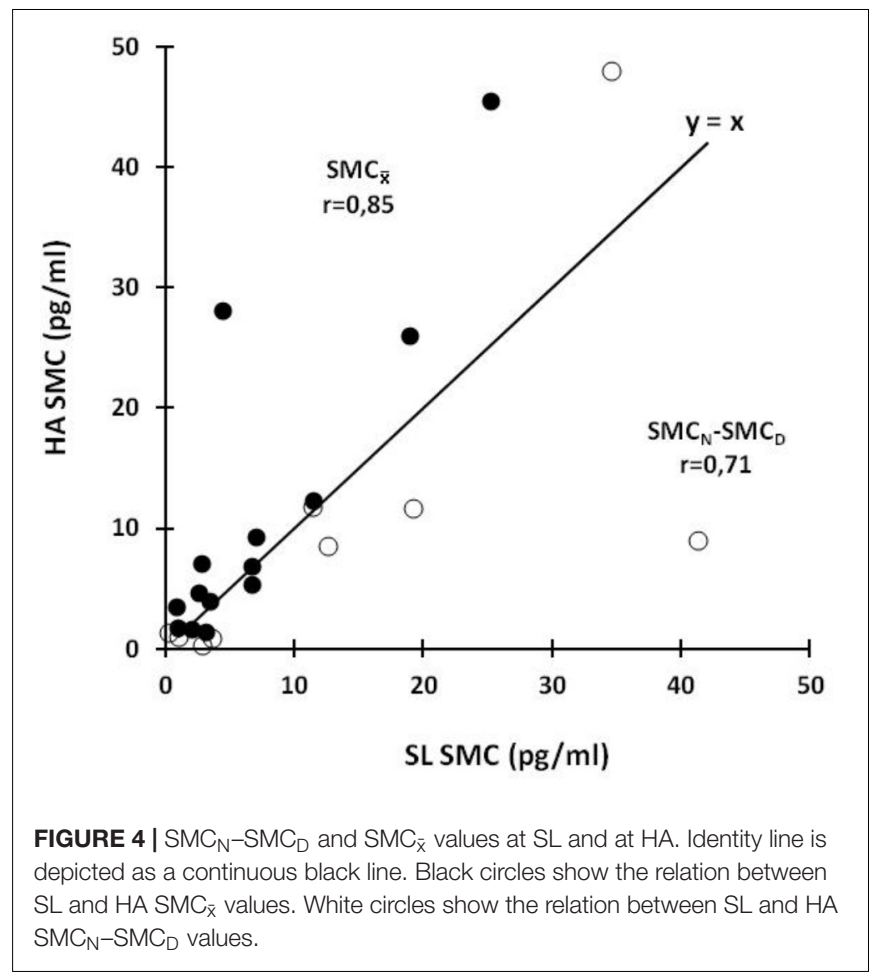

(van Faassen et al., 2017). Like in oral mucosa (Chaiyarit et al., 2017), melatonin may be also locally produced in salivary glands (van Faassen et al., 2017). Whether related or not with plasma melatonin, SMC shows in the present work a clear rhythmicity, that may even represent changes occurring at tissue level. An ELISA kit used in the present work yielded SMC values very similar to those reported by others (Lushington et al., 2002; Verheggen et al., 2012).

Mean $\mathrm{SMC}_{\mathrm{N}}$ and $\mathrm{SMC}_{\mathrm{D}}$ values differ at SL but not at $\mathrm{HA}$ (Figure 1). $\mathrm{SMC}_{\mathrm{N}}-\mathrm{SMC}_{\mathrm{D}}$ considered, in the present study, as the amplitude of daily melatonin variation, correlates with $\mathrm{SMC}_{\overline{\mathrm{x}}}$ (the average value around which the oscillation occurs) more strongly at SL than at HA (Figure 2). Distortions of SMC rhythm as shown to occur at HA (Figures 1, 2) may implicate a deregulation of melatonin-dependent periodic processes. High amplitudes in circadian melatonin rhythmicity may prevent and/or delay the development of diabetes (Hardeland, 2017). The amplitude of daily melatonin oscillation, on the other hand, diminishes in the elderly (Gubin et al., 2006; Kim et al., 2014).

Disruption of body timekeeping, implicates deregulation of body functions (Cipolla-Neto et al., 2014; O’Neill and Feeney, 2014). Three weeks of circadian disruption induce a prediabetic condition in otherwise healthy subjects (Buxton et al., 2012). Energy metabolism unbound from circadian pacemakers associates to obesity, diabetes, cardiovascular disease, and cancer (Miller et al., 2010; Blask et al., 2014; Zubidat and Haim, 2017). $\mathrm{SMC}_{\mathrm{N}}-\mathrm{SMC} \mathrm{C}_{\mathrm{D}}$, as well as, absolute values of $\mathrm{SMC}_{\mathrm{N}}$ and SMC $_{D}$ loosening their relation with RQ at HA (Figure 3) could mean a decoupling of energy metabolism from circadian control, a possibility that certainly has further to be elucidated. It may be noticed, however, that even acute adequation of energy metabolism to HA exposure is yet far from reaching a consensus (Chicco et al., 2018). It may be provisionally assumed, however, that mistiming of melatonin circadian rhythmicity may represent a metabolic risk factor, particularly under conditions combining shift work with hypoxia as being usual in Chilean Andes.

Deregulation of circadian melatonin rhythmicity may result from changes in oxygen supply. Hypoxia also implicates an increase in sympathetic activity. Sympathetic afferent nerves of the pineal gland activate an $N$-acetyltransferase, the rate-limiting enzyme for melatonin synthesis. Beta-blockers, older age and a higher body mass, on the other hand, have been found to lower nocturnal urinary 6-sulfatoxymelatonin levels (Davis et al., 2001). Melatonin secretion may, moreover, additionally be altered at HA by hypocapnia prevailing in newcomers at HA. Neurons of suprachiasmatic nucleus are, in fact, particularly sensitive to $\mathrm{pH}$ (Chen et al., 2009).

Individual values of $\mathrm{SMC}_{\mathrm{N}}-\mathrm{SMC}_{\mathrm{D}}$ and $\mathrm{SMC}_{\overline{\mathrm{x}}}$ observed at $\mathrm{SL}$, respectively, correlate with the corresponding value at HA (Figure 4). Individual patterns in melatonin circadian rhythmicity as observed at SL, thus, appear largely to be conserved at HA. Individual circadian melatonin rhythmicity seems, indeed, to remain relatively stable (Fernández et al., 2017). With exception of sedation and/or artificial ventilation (Olofsson et al., 2004), neither activity, posture, sleep, nor menstrual phase appear to affect individual circadian rhythm of melatonin (Cain et al., 2010). From one subject to another one, nocturnal melatonin concentration can, on the other hand, differ considerably (Zeitzer et al., 1999). Some people seem to be able to rapidly modify their melatonin secretion pattern, as well as, to readily adapt to rotating shift schedules (Quera-Salva et al., 1997). Similarly, physiological adjustments to acute HA exposure vary, indeed, substantially from one subject to another. Individual characteristics of circadian melatonin rhythmicity, yet to be defined, may well relate with the capacity to adequately deal with challenges of the body timing system affecting energy metabolism in health and disease.

To summarize, a rapid ascent to an altitude of about 3,000 $\mathrm{m}$ a.s.l., as usual under working conditions in the Andes, tends to override the night-day difference of SMC and to weaken the relations between SMC with RQ, thus, potentially deregulating melatonin-dependent timing of body functions, affecting energy metabolism. Individual SL circadian profile of SMC tends, on the other hand, to be maintained at HA. The SL profile of melatonin circadian rhythm may be further on explored for its potential to predict individual tolerance to challenges of the body timing system at HA.

\section{AUTHOR CONTRIBUTIONS}

$\mathrm{CB}, \mathrm{CW}-\mathrm{Z}$, JS-U, ML, and MT were mostly implicated in the experimental design, logistics, and development of the experimental work at SL and HA. MT, CW-Z, NDG, ML, HV, MS-F, EV, OA, JS-U, H-CG, and CB substantially contributed to the conception of the work, data analysis and 
manuscript revision, approved the final version, and agree to be accountable for the whole work. The M.Sc. thesis of MT at the Faculty of Health Sciences, University of Antofagasta, is mainly based on this work.

\section{FUNDING}

This study was supported by FONDECYT Chile (Project $\mathrm{N}^{\circ} 1100161$ ) and Bundesministerium für Bildung und Forschung (Project CHLI2Anb, Domeyko-Center) Germany is gratefully acknowledged.

\section{REFERENCES}

Acuña-Castroviejo, D., Escames, G., Leon, J., Carazo, A., and Khaldy, H. (2003). Mitochondrial regulation by melatonin and its metabolites. Adv. Exp. Med. Biol. 527, 549-557. doi: 10.1007/978-1-4615-0135-0_63

Alkozi, H. A., Wang, X., Perez de Lara, M. J., and Pintor, J. (2017). Presence of melanopsin in human crystalline lens epithelial cells and its role in melatonin synthesis. Exp. Eye Res. 154, 168-176. doi: 10.1016/j.exer.2016.11.019

Andlauer, P., Reinberg, A., Fourré, L., Battle, W., and Duverneuil, G. (1979). Amplitude of the oral temperature circadian rhythm and the tolerance to shift work. J. Physiol. 75, 507-512.

Archer, S. N., Laing, E. E., Möller-Levet, C. S., van der Veen, D. R., Bucca, G., Lazar, A. S., et al. (2014). Mistimed sleep disrupts circadian regulation of the human transcriptome. Proc. Natl. Acad. Sci. U.S.A. 111, E682-E691. doi: 10.1073/pnas. 1316335111

Arendt, J. (1996). Melatonin. BMJ 312, 1242-1243. doi: 10.1136/bmj.312.7041.1242

Arendt, J. (2012). Biological rhythms during residence in polar regions. Chronobiol. Int. 29, 379-394. doi: 10.3109/07420528.2012.668997

Beale, A. D., Whitmore, D., and Moran, D. (2016). Life in a dark biosphere: a review of circadian physiology in "arrhythmic" environments. J. Comp. Physiol. B 186, 947-968. doi: 10.1007/s00360-016-1000-6

Benloucif, S., Burgess, H. J., Klerman, E. B., Lewy, A. J., Middleton, B., Murphy, P. J., et al. (2008). Measuring melatonin in humans. J. Clin. Sleep Med. 4, 66-69.

Berson, D. M., Dunn, F. A., and Takao, M. (2002). Phototransduction by retinal ganglion cells that set the circadian clock. Science 295, 1070-1073. doi: 10.1126/ science. 1067262

Blask, D. E., Dauchy, R. T., Dauchy, E. M., Mao, L., Hill, S. M., Greene, M. W., et al. (2014). Light exposure at night disrupts host/cancer circadian regulatory dynamics: impact on the Warburg effect, lipid signaling and tumor growth prevention. PLoS One 9:e102776. doi: 10.1371/journal.pone.0102776

Buxton, O. M., Cain, S. W., O'Connor, S. P., Porter, J. H., Duffy, J. F., Wang, W., et al. (2012). Adverse metabolic consequences in human of prolonged sleep restriction combined with circadian disruption. Sci. Transl. Med. 4:129ra43. doi: 10.1126/scitranslmed.3003200

Cain, S. W., Dennison, C. F., Zeitzer, J. M., Guzik, A. M., Khalsa, S. B., Santhi, N., et al. (2010). Sex differences in phase angle of entrainment and melatonin amplitude in humans. J. Biol. Rhythms 25, 288-296. doi: 10.1177/ 0748730410374943

Chaiyarit, P., Luengtrakoon, K., Wannakasemsuk, W., Vichitrananda, V., Klanrit, P., Hormdee, D., et al. (2017). Biological functions of melatonin in relation to pathogenesis of oral lichen planus. Med. Hypotheses 104, 40-44. doi: 10.1016/j.mehy.2017.05.021

Chakir, I., Dumont, S., Pévet, P., Ouarour, A., Challet, E., and Vuillez, P. (2015). Pineal melatonin is a circadian time-giver for leptin rhythm in Syrian hamsters. Front. Neurosci. 9:190. doi: 10.3389/fnins.2015.00190

Chen, C. H., Hsu, Y. T., Chen, C. C., and Huang, R. C. (2009). Acid-sensing ion channels in neurones of the rat suprachiasmatic nucleus. J. Physiol. 587, 1727-1737. doi: 10.1113/jphysiol.2008.166918

Chicco, A., Le, C., Gnaiger, E., Dreyer, H., Muyskens, J., D’Alessandro, A., et al. (2018). Adaptive remodeling of skeletal muscle energy metabolism in highaltitude hypoxia: lessons from AltitudeOmics. J. Biol. Chem. 293, 6659-6671. doi: 10.1074/jbc.RA117.000470

\section{ACKNOWLEDGMENTS}

Thanks are due to Mr. Aldo Valdebenito for technical support, as well as, to University of Antofagasta students for their enthusiastic participation as volunteers in the present study. We also thank very much Professor Juan Ahumada, Director of Escuela E-20, for providing access and facilities in Caspana. We acknowledge moreover the critical reading of the manuscript by Dr. Stefan Mendt from Institute of Physiology, Center of Space Medicine and Extreme Environments Berlin, Charité Universitätsmedizin Berlin, Germany, as well as, the very helpful advice provided by two reviewers from Frontiers.

Cipolla-Neto, J., Amaral, F. G., Afeche, S. C., Tan, D. X., and Reiter, R. J. (2014). Melatonin, energy metabolism, and obesity: a review. J. Pineal Res. 56, 371-381. doi: 10.1111/jpi.12137

Connett, R. J., Honig, C. R., Gayeski, T. E., and Brooks, G. A. (1990). Defining hypoxia: a systems view of VO2, glycolysis, energetics, and intracellular PO2. J. Appl. Physiol. 68, 833-842. doi: 10.1152/jappl.1990.68.3.833

Coomans, C. P., van den Berg, S. A., Lucassen, E. A., Houben, T., Pronk, A. C., van der Spek, R. D., et al. (2013). The suprachiasmatic nucleus controls circadian energy metabolism and hepatic insulin sensitivity. Diabetes Metab. Res. Rev. 62, 1102-1108. doi: 10.2337/db12-0507

Coste, O., Beaumont, M., Batéjat, D., Van Beers, P., Charbuy, H., and Touitou, Y. (2004). Hypoxic depression of melatonin secretion after simulated long duration flights in man. J. Pineal Res. 37, 1-10. doi: 10.1111/j.1600-079X.2004. 00128.x

Coste, O., Van Beers, P., and Touitou, Y. (2009). Hypoxia-induced changes in recovery sleep, core body temperature, urinary 6-sulphatoxymelatonin and free cortisol after a simulated long-duration flight. J. Sleep Res. 18, 454-465. doi: 10.1111/j.1365-2869.2009.00744.x

Cudney, L. E., Sassi, R., Behr, G. A., Streiner, D. L., Minuzzi, L., Moreira, J. C., et al. (2014). Alterations in circadian rhythms are associated with increased lipid peroxidation in females with bipolar disorder. Int. J. Neuropsychopharmacol. 17, 715-722. doi: 10.1017/S1461145713001740

Davis, S., Kaune, W. T., Mirick, D. K., Chen, C., and Stevens, R. G. (2001). Residential magnetic fields, light-at-light, and nocturnal urinary 6sulfatoxymelatonin concentration in women. Am. J. Epidemiol. 154, 591-600. doi: 10.1093/aje/154.7.591

Fernández, F., Nyhuis, C. C., Anand, P., Demara, B. I., Ruby, N. F., Spanò, G., et al. (2017). Young children with down syndrome show normal development of circadian rhythms, but poor sleep efficiency: a cross-sectional study across the first 60 months of life. Sleep Med. 33, 134-144. doi: 10.1016/j.sleep.2016. 12.026

Gooneratne, N. S., Metlay, J. P., Guo, W., Pack, F. M., Kapoor, S., and Pack, A. I. (2003). The validity and feasibility of saliva melatonin assessment in the elderly. J. Pineal Res. 34, 88-94. doi: 10.1034/j.1600-079X.2003.02945.x

Gubin, D. G., Gubin, G. D., Waterhouse, J., and Weinert, D. (2006). The circadian body temperature rhythm in the elderly: effect of single daily melatonin dosing. Chronobiol. Int. 23, 639-658. doi: 10.1080/07420520600650612

Haim, A., and Zubidat, A. E. (2015). Artificial light at night: melatonin as a mediator between the environment and epigenome. Philos. Trans. R. Soc. Lond. B Biol. Sci. 370:20140121. doi: 10.1098/rstb.2014.0121

Hardeland, R. (2015). Melatonin and circadian oscillators in aging-a dynamic approach to the multiply connected players. Interdiscip. Top. Gerontol. 40, 128-140. doi: 10.1159/000364975

Hardeland, R. (2017). Melatonin and the pathologies of weakened or dysregulated circadian oscillators. J. Pineal Res. 62:e12377. doi: 10.1111/jpi.12377

Hardeland, R., Cardinali, D. P., Srinivasan, V., Spence, D. W., Brown, G. M., and Pandi-Perumal, S. R. (2011). Melatonin - a pleiotropic, orchestrating regulator molecule. Prog. Neurobiol. 93, 350-384. doi: 10.1016/j.pneurobio.2010.12.004

Hardeland, R., Madrid, J. A., Tan, D.-X., and Reiter, R. J. (2012). Melatonin, the circadian multioscillator system and health: the need for detailed analyses of peripheral melatonin signaling. J. Pineal Res. 52, 139-166. doi: 10.1111/j.1600079X.2011.00934.x 
Hernández, C., Abreu, J., Abreu, P., Castro, A., and Jiménez, A. (2007). Nocturnal melatonin plasma levels in patients with OSAS: the effect of CPAP. Eur. Respir. J. 30, 496-500. doi: 10.1183/09031936.00051906

Jiménez-Ortega, V., Cano Barquilla, P., Fernández-Mateos, P., Cardinali, D. P., and Esquifino, A. I. (2012). Cadmium as an endocrine disruptor: correlation with anterior pituitary redox and circadian clock mechanisms and prevention by melatonin. Free Radic. Biol. Med. 53, 2287-2297. doi: 10.1016/j.freeradbiomed. 2012.10.533

Kaur, C., Srinivasan, K. N., Singh, J., Peng, C. M., and Ling, E. A. (2002), Plasma melatonin, pinealocyte morphology, and surface receptors/antigen expression on macrophages/microglia in the pineal gland following a high altitude exposure. J. Neurosci. Res. 67, 533-543. doi: 10.1002/jnr.10136

Kim, S. J., Benloucif, S., Reid, K. J., Weintraub, S., Kennedy, N., Wolfe, L. F., et al. (2014). Phase-shifting response to light in older adults. J. Physiol. 592, 189-202. doi: 10.1113/jphysiol.2013.262899

Korkmaz, A., Rosales-Corral, S., and Reiter, R. J. (2012). Gene regulation by melatonin linked to epigenetic phenomena. Gene 503, 1-11. doi: 10.1016/j.gene. 2012.04.040

Kräuchi, K., Cajochen, C., Pache, M., Flammer, J., and Wirz-Justice, A. (2006). Thermoregulatory effects of melatonin in relation to sleepiness. Chronobiol. Int. 23, 475-484. doi: 10.1080/07420520500545854

Li, C., Clinton Sprott, J., Akgul, A., Iu, H. H. C., and Zhao, Y. (2017). A new chaotic oscillator with free control. Chaos 27:083101. doi: 10.1063/1.4997051

Lin, S. Z., Li, B., Lan, G., and Feng, X. Q. (2017). Activation and synchronization of the oscillatory morphodynamics in multicellular monolayer. Proc. Natl. Acad. Sci. U.S.A. 114, 8157-8162. doi: 10.1073/pnas. 1705492114

Lloyd, D., and Rossi, E. L. (1993). Biological rhythms as organization and information. Biol. Rev. Camb. Philos. Soc. 68, 563-577. doi: 10.1111/j.1469185X.1993.tb01244.x

Lucas, R. J., Peirson, S. N., Berson, D. M., Brown, T. M., Cooper, H. M., Czeisler, C. A., et al. (2014). Measuring and using light in the melanopsin age. Trends Neurosci. 37, 1-9. doi: 10.1016/j.tins.2013.10.004

Luchetti, F., Canonico, B., Betti, M., Arcangeletti, M., Pilolli, F., Piroddi, M., et al. (2010). Melatonin signaling and cell protection function. FASEB J. 24, 3603-3624. doi: 10.1096/fj.10-154450

Lushington, K., Galka, R., Sassi, L. N., Kennaway, D. J., and Dawson, D. (2002). Extraocular light exposure does not phase shift saliva melatonin rhythms in sleeping subjects. J. Biol. Rhythms 17, 377-386. doi: 10.1177/ 074873002129002582

Maciel, F. E., Ramos, B. P., Geihs, M. A., Vargas, M. A., Cruz, B. P., Meyer-Rochow, V. B., et al. (2010). Effects of melatonin in connection with the antioxidant defense system in the gills of the estuarine crab Neohelice granulata. Gen. Comp. Endocrinol. 165, 229-236. doi: 10.1016/j.ygcen.2009.07.009

McGinnis, G. R., Tang, Y., Brewer, R. A., Brahma, M. K., Stanley, H. L., Shanmugan, G., et al. (2017). Genetic disruption of the cardiomyocyte circadian clock differentially influences insulin-mediated processes in the heart. J. Mol. Cell Cardiol. 110, 80-95. doi: 10.1016/j.yjmcc.2017.07.005

Miller, D., Bierman, A., Figueiro, M., Schernhammer, E., and Rea, M. (2010). Ecological measurements of light exposure, activity, and circadian disruption. Light. Res. Technol. 42, 271-284. doi: 10.1177/1477153510367977

Mirick, D. K., Bhatti, P., Chen, C., Nordt, F., Stanczyk, F. Z., and Davis, S. (2013). Night shift work and levels of 6-sulfatoxymelatonin and cortisol in men. Cancer Epidemiol. Biomarkers Prev. 22, 1079-1087. doi: 10.1158/1055-9965.EPI-121377

Mortola, J. P. (2007). Hypoxia and circadian patterns. Respir. Physiol. Neurobiol. 158, 274-279. doi: 10.1016/j.resp.2007.02.005

Mortola, J. P. (2017). Gender and the circadian pattern of body temperature in normoxia and hypoxia. Respir. Physiol. Neurobiol. 245, 4-12. doi: 10.1016/j.resp. 2016.11.002

Najjar, R. P., Wolf, L., Tallard, J., Schlangen, L. J., Salam, A., Cajochen, C., et al. (2014). Chronic artificial blue-enriched white light is an effective countermeasure to delayed circadian phase and neurobehavioral decrements. PLoS One 9:e102827. doi: 10.1371/journal.pone.0102827

Nehela, Y., and Killiny, N. (2018). Infection with phytopathogenic bacterium inhibits melatonin biosynthesis, decreases longevity of its vector, and suppresses the free radical-defense. J. Pineal Res. doi: 10.1111/jpi.12511 [Epub ahead of print]. doi: 10.1111/jpi.12511
Olofsson, K., Alling, C., Lundberg, D., and Malmros, C. (2004). Abolished circadian rhythm of melatonin secretion in sedated and artificially ventilated intensive care patients. Acta Anaesthesiol. Scand. 48, 679-684. doi: 10.1111/j.0001-5172. 2004.00401.x

O’Neill, J. S., and Feeney, K. A. (2014). Circadian redox and metabolic oscillations in mammalian systems. Antioxid. Redox Signal. 20, 2966-2981. doi: 10.1089/ ars. 2013.5582

Panda, S., Provencio, I., Tu, D. C., Pires, S. S., Rollag, M. D., Castrucci, A. M., et al. (2003). Melanopsin is required for non-image-forming photic responses in blind mice. Science 301, 525-527. doi: 10.1126/science.10 86179

Peschke, E., Bähr, I., and Mühlbauer, E. (2013). Melatonin and pancreatic islets: interrelationships between melatonin, insulin and glucagon. Int. J. Mol. Sci. 14, 6981-7015. doi: 10.3390/ijms14046981

Pfeffer, M., Korf, H. W., and Wicht, H. (2017). Synchronizing effects of melatonin on diurnal and circadian rhythms. Gen. Comp. Endocrinol. 258, 215-221. doi: 10.1016/j.ygcen.2017.05.013

Pulivarthy, S. R., Tanaka, N., Welsh, D. K., De Haro, L., Verma, I. M., and Panda, S. (2007). Reciprocity between phase shifts and amplitude changes in the mammalian circadian clock. Proc. Natl. Acad. Sci. U.S.A. 104, 20356-20361. doi: 10.1073/pnas.0708877104

Quera-Salva, M. A., Guilleminault, C., Claustrat, B., Defrance, R., Gajdos, P., McCann, C. C., et al. (1997). Rapid shift in peak melatonin secretion associated with improved performance in short shift work schedule. Sleep 20, 1145-1150.

Rapp, P. E. (1987). Why are so many biological systems periodic? Prog. Neurobiol. $29,261-273$.

Reddy, A. B., and O'Neill, J. S. (2010). Healthy clocks, healthy body, healthy mind. Trends Cell Biol. 20, 36-44. doi: 10.1016/j.tcb.2009.10.005

Reinberg, A., and Ashkenazi, I. (2008). Internal desynchronization of circadian rhythms and tolerance to shift work. Chronobiol. Int. 25, 625-643. doi: 10.1080/ 07420520802256101

Reiter, R. J., Tan, D.-X., and Fuentes-Broto, L. (2010). Melatonin: a multitasking molecule. Prog. Brain Res. 181, 127-151. doi: 10.1016/S0079-6123(08)81008-4

Schroeder, C. E., and Lakatos, P. (2009). Low-frequency neuronal oscillations as instruments of sensory selection. Trends Neurosci. 32, 9-18. doi: 10.1016/j.tins. 2008.09.012

Smolensky, M. H., Hermida, R. C., Reinberg, A., Sackett-Lundeen, L., and Portaluppi, F. (2016). Circadian disruption: new clinical perspective of disease pathology and basis for chronotherapeutic intervention. Chronobiol. Int. 33, 1101-1119. doi: 10.1080/07420528.2016.1184678

Swanson, G. R., Gorenz, A., Shaikh, M., Desai, V., Kaminsky, T., Van Den Berg, J., et al. (2016). Night workers with circadian misalignment are susceptible to alcohol-induced intestinal hyperpermeability with social drinking. Am. J. Physiol. Gastrointest. Liver Physiol. 311, G192-G201. doi: 10.1152/ajpgi.00087. 2016

Tan, D.-X., Hardeland, R., Manchester, L. C., Paredes, S. D., Korkmaz, A., Sainz, R. M., et al. (2010). The changing biological roles of melatonin during evolution: from an antioxidant to signals of darkness, sexual selection and fitness. Biol. Rev. Camb. Philos. Soc. 85, 607-623. doi: 10.1111/j.1469-185X.2009. 00118.x

Tan, D. X., Manchester, L. C., Liu, X., Rosales-Corral, S. A., Acuña-Castroviejo, A., and Reiter, R. J. (2013). Mitochondria and chloroplasts as the original sites of melatonin synthesis: a hypothesis related to melatonin's primary function and evolution in eukaryotes. J. Pineal Res. 54, 127-138. doi: 10.1111/jpi. 12026

Thurley, K., Herbst, C., Wesener, F., Koller, B., Wallach, T., Maier, B., et al. (2017). Principles for circadian orchestration of metabolic pathways. Proc. Natl. Acad. Sci. U.S.A. 114, 1572-1577. doi: 10.1073/pnas.1613103114

Thut, G., Miniussi, C., and Gross, J. (2012). The functional importance of rhythmic activity in the brain. Curr. Biol. 22, R658-R663. doi: 10.1016/j.cub.2012.06.061

Top, D., and Young, M. W. (2017). Coordination between differentially regulated circadian clocks generates rhythmic behavior. Cold Spring Harb. Perspect. Biol. doi: 10.1101/cshperspect.a033589 [Epub ahead of print].

Torres-Farfán, C., Méndez, N., Abarzúa-Catalán, L., Vilches, N., Valenzuela, G. J., and Serón-Ferré, M. (2011). A circadian clock entrained by melatonin is ticking in the rat fetal adrenal. Endocrinology 152, 1891-1900. doi: 10.1210/en.20101260 
Tran, D., Sow, M., Camus, L., Ciret, P., and Massabuau, J. C. (2016). In the darkness of the polar night, scallops keep on a steady rhythm. Sci. Rep. 6:32435. doi: 10.1038/srep32435

Tsang, A. H., Barclay, J. L., and Oster, H. (2013). Interactions between endocrine and circadian systems. J. Mol. Endocrinol. 52, R1-R16. doi: 10.1530/JME-130118

Unfried, C., Burbach, G., Korf, H. W., and von Gall, C. (2010). Melatonin receptor 1-dependent gene expression in the mouse pars tuberalis as revealed by cDNA microarray analysis and in situ hybridization. J. Pineal Res. 48, 148-156. doi: 10.1111/j.1600-079X.2009.00738.x

van Faassen, M., Bischoff, R., and Kema, I. (2017). Relationship between plasma and salivary melatonin and cortisol investigated by LCMS/MS. Clin. Chem. Lab. Med. 55, 1340-1348. doi: 10.1515/cclm-20160817

Verheggen, R. J., Jones, H., Nyakayiru, J., Thompson, A., Groothuis, J. T., Atkinson, G., et al. (2012). Complete absence of evening melatonin increases in tetraplegics. FASEB J. 26, 3059-3064. doi: 10.1096/fj.12-205401

Voultsios, A., Kennaway, D. J., and Dawson, D. (1997). Salivary melatonin as a circacian phase marker: validation and comparison to plasma melatonin. J. Biol. Rhythms 12, 457-466. doi: 10.1177/074873049701200507

Zaldívar Larraín, M. J. (2013). Estadísticas de Accidentabilidad. SUSESO. Available at: https://www.suseso.cl/609/articles-18981_archivo_01.pdf
Zeitzer, J. M., Daniels, J. E., Duffy, J. F., Klerman, E. B., Shanahan, T. L., Dijk, D. J., et al. (1999). Do plasma melatonin concentrations decline with age? Am. J. Med. 107, 432-436. doi: 10.1016/S0002-9343(99)00266-1

Zelano, C., Jiang, H., Zhou, G., Arora, N., Schuele, S., Rosenow, J., et al. (2016). Nasal respiration entrains human limbic oscillations and modulates cognitive function. J. Neurosci. 36, 12448-12467. doi: 10.1523/JNEUROSCI.2586-16.2016 Zubidat, A. E., and Haim, A. (2017). Artificial light-at-night - a novel lifestyle risk factor for metabolic disorder and cancer morbidity. J. Basic Clin. Physiol. Pharmacol. 28, 295-313. doi: 10.1515/jbcpp-2016-0116

Conflict of Interest Statement: The authors declare that the research was conducted in the absence of any commercial or financial relationships that could be construed as a potential conflict of interest.

Copyright (c) 2018 Tapia, Wulff-Zottele, De Gregorio, Lang, Varela, Serón-Ferré, Vivaldi, Araneda, Silva-Urra, Gunga and Behn. This is an open-access article distributed under the terms of the Creative Commons Attribution License (CC BY). The use, distribution or reproduction in other forums is permitted, provided the original author(s) and the copyright owner(s) are credited and that the original publication in this journal is cited, in accordance with accepted academic practice. No use, distribution or reproduction is permitted which does not comply with these terms. 